\title{
ALGUNAS EXPRESIONES MEXICANAS RELATIVAS A LA MUERTE
}

Es en verdad impresionante la riqueza de las expresiones mexicanas que aluden a la muerte. Tratar de recogerlas todas resulta empresa lenta y detenida; reúno aquí únicamente -como adelanto de un estudio más detallado y completo- las voces y locuciones populares que se emplean en sustitución de los verbos morir o matar y que se basan, metafóricamente, en la manera de morir los animales ${ }^{1}$. Los materiales han sido recogidos en la ciudad de México, punto de confluencia de todas las corrientes lingüísticas del país y a la vez manantial riquísimo de innovaciones expresivas; cuando me consta que el término recogido es sólo provincial, lo hago notar.

\section{ESTUdios CITADOS CON MAYOR FRECUENCIA}

Aguilar $=$ José R. Aguilar, Los métodos criminales en México, México, 1941 (pp. 185-218: "Diccionario del caló mexicano").

Amor = Ricardo Amor, Diccionario del hampa, México, 1947.

Casares=Julio Casares, Diccionario ideológico de la lengua española, Barcelona, 1954 .

Correas =Gonzalo Correas, Vocabulario de refranes y frases proverbiales, Madrid, 1924 .

Covarrubias=Sebastián de Covarrubias, Tesoro de la lengua castellana, ed. de Martín de Riquer, Barcelona, 1943.

Chabat=Carlos G. Chabat, Diccionario de caló; el lenguaje del hampa en México, Guadalajara, $195^{6}$.

Jiménez=A. Jiménez, Picardia mexicana, México, 1960.

Kany=Charles E. Kany, American-Spanish euphemisms, Berkeley and Los Angeles, 1960.

Malaret=Augusto Malaret, Diccionario de americanismos, $3^{\text {a }}$ ed., Buenos Aires, 1946 .

Padrón=Francisco Padrón, El médico y el folklore, San Luis Potosí, 1956. Ríos=Eduardo E. Ríos, "Nuestras bromas con la muerte", $A b s, 24$ (1960), $482-491$.

1 Quedan excluidas, por consiguiente, otras muchas expresiones semejantes en las cuales, aunque se alude al mundo animal, no se hace referencia a la muerte misma de las bestias. Dar a uno sus camarones, por ejemplo, significa 'matar', pero en este caso la expresión no se refiere a la manera de morir los camarones; lo mismo cuando se dice que a una persona se la cargaron las chinches, o que se la comieron los zopilotes, etc. Todas estas expresiones rebasan los límites que aquí me he impuesto. 
Rubio, A=Dario Rubio, La anarquia del lenguaje en la América española, México, 1925 (2 vols.).

Rubio, $\mathrm{R}=$ Darío Rubio, Refranes, proverbios y dichos y dicharachos mexicanos, $2^{\text {a }}$ ed., México, 1940 (2 vols.).

Santamaría, $\mathrm{A}=$ Francisco J. Santamaría, Diccionario general de americanismos, México, 1942 (9 vols.).

Santamaría, $\mathrm{M}=\mathrm{Id}$., Diccionario de mejicanismos, México, 1959.

Trejo=Amulfo Trejo Dueñes, Contribución al estudio del léxico de la delincuencia, México, 1959 (tesis doctoral).

Viotti=Manuel Viotti, Dicionário da giria brasileira, São Paulo, 1945. Wagner, $\mathrm{M}=$ Max Leopold Wagner, "Mexikanisches Rotwelsch", ZRPh, 39 (1919), 513-550.

Wagner, $\mathbf{P}=$ M. L. Wagner, "Ein mexikanisch-amerikanischer Argot: das Pachuco", RJ, 6 (1953-54), 237-266.

\section{A T A R}

$\S$ 1. Sacrificar. Ampliación irónica del sentido correspondiente a la segunda acepción académica: 'Matar, degollar las reses para el consumo'. Exento, creo, de toda connotación religiosa: “¡Pobrecito Tomás! Lo sacrificaron por buscapleitos". Es poco usado. Probablemente también el verbo matancear deba relacionarse con el sacrificio de las reses en el rastro; sería derivado de matanza en la acepción de 'faena de matar cerdos' o cualquier otro ganado; matancero es, en casi toda Hispanoamérica, el 'jifero, el que mata reses y las descuartiza; carnicero o tablajero' (Santamaría, M): "A chillidos de puerco, oídos de matancero" (Rubio, R, I, 1 1); y en el Brasil matança es el nombre del matadero público mismo (Viotti). Matancear podría ser también uno de los casos de alargamiento fonético a que tan aficionado es el hablante popular mexicano: por matar se dice también matanguear; por emborracharse, emborrachecerse; por sacar, sacatear (cruce con zacate); por sí, simón, etc. En Colombia, con el mismo sentido de 'matar, asesinar', se usa la expresión pasar al palo², correspondiente a la general mandar al matadero.

$\S$ 2. Más empleado que los anteriores es el verbo carnear 'herir y matar con arma blanca en un combate o alcance' (Santamaría, M), o simplemente 'matar con arma blanca' en cualquier ocasión ${ }^{3}$ (Santamaría, A). Su acepción primaria es la de 'matar y descuartizar las reses para aprovechar su carne', que el $D R A E$ recoge como americanismo general. De ahí pasa a aplicarse a personas ${ }^{4}$. Es muy usado

2 "Tal vez su origen se base en la costumbre de 'pasar al palo' o amarrar en un palo (bramadero) la res destinada al sacrificio" (F. Sánchez ArÉvalo, "Notas sobre el lenguaje de Río de Oro", BICC, 6, 1950, 214-252; en especial, p. 242).

3 Max L. WAGNer, Lingua e dialetti dell'America spagnola, Firenze, 1949, p. 4o: "Carnear (Messico) ferire o uccidere all'arma bianca".

4 Kany, 25: "Carnear means both 'to slaughter animais' and 'to kill persons', as in Al que es confiado y no se precave, lo carnean»". 
sobre todo en la Argentina ${ }^{5}$ (Rosenblat, $B D H$, 2, p. 305), en el Uruguay (Malaret), en Chile (Z. Rodríguez, Diccionario de chilenismos, Santiago, 1875) y aun en la provincia brasileña de Rio Grande do Sul (D. Granada, Vocabulario rioplatense razonado, Montevideo, 1957). En el mismo Brasil, carneador es el 'local onde habitualmente se abate a rês, matadouro' (Viotti). En Nicaragua carnear es 'descuartizar reses, generalmente en despoblado y en forma clandestina' (Malaret). En Chile, además, 'engañar a alguien perjudicándole en sus intereses' (Santamaría, A; $D R A E$ ); este mismo valor - 'engañar, burlarse de alguien'- se conoce también en México. En español, desde antiguo, carnero valía por 'sepultura'6 (DCEC); ef. catalán carner 'cementerio'; esto explica la expresión rústica argentina cantar pa'l carnero 'morir' (Kany, 23; Martin Fierro, I, v. 1236). El verbo carnear 'matar' parece no ser enteramente desconocido en España: "Ben Mohamed, rey de Baeza, fue carneado por sus súbditos aquí en Almodóvar" (C. J. CelA, Primer viaje andaluz, Barcelona, 1959, p. 201; a no ser que se trate de un americanismo adoptado por Cela); carnizar significa, en Andalucía, 'sacrificar una res y prepararla para la venta' (A. Alcalá Venceslada, Vocabulario andaluz, Madrid, 1951). Derivado de carnero es el verbo carnerear que recoge el DRAE: 'matar, degollar reses, en pena de haber hecho algún daño el ganado'. Casares cita la locución hacer carne, 'hablando de los animales carnívoros, matar', que también puede aplicarse a personas: 'herir o matar a otro'. La misma ampliación en el uso que ha experimentado el verbo carnear en México, se da con el verbo beneficiar, usual en parte de América con el sentido de 'matar el ganado': "Había olido la sangre de una res que fue beneficiada allí en la mañana" (R. Gallegos, Doña Bárbara, México, 1954, p. 283). De aquí, “in some regions, as in Guatemala, beneficiar is applied to persons in the sense of fusilar and of matar or asesinar, as in "La escolta se benefició al reo mediante la aplicación de la ley fuga»" (Kany, 25). Idéntica traslación en el caso de los verbos atocinar y acochinar, que recoge Casares: "atocinar, tr. "partir el cerdo en canal; hacer los tocinos y salarlos'; fig. y fam. 'matar a uno alevosamente'; acochinar, tr. fam. 'matar a uno que no puede huir ni defenderse" ". Ninguno de los dos parece usarse en México.

$\S 3$. Filetear. En la lengua popular se toma por hacer filetes de una persona, descuartizarla, matarla: "Se lo filetiaron porque los

5 R. Monner Sans, Notas al castellano en la Argentina, Buenos Aires, 1944, p. 49: "De pez se hizo pescar, que significa coger peces sin duda para comerlos; de carne haríamos carnear, que significaría coger y matar ganado, reses, carne en una palabra, para comerla". Aplicado a seres humanos: "la tropa, verdaderamente carneada, retrocedió" (M. DE Toro GISBERT, "El idioma de un argentino", BRAE, 9, 1922, p. 708).

6 Significaba también lugar 'donde se guarda la carne' (Nebrija, Vocabulario español-latino). 
traicionó". Sería, así, derivado de filete 'lonja de carne magra'; además, el sustantivo fileteo expresa la 'acción de hacer filetes de la carne de res, o sacarle a ésta el filete' (Santamaría, M). Sin embargo, creo que filetear se deriva de filero 'cuchillo' en el argot del hampa (Aguilar, 201; Ramos i Duarte, Diccionario de mejicanismos, México, 1895) o también 'navaja, puñal' (Amor, 105; Chabat; Trejo, 120); lo' mismo en la germanía brasileña: fileiro 'canivete' (Viotti); filosa por 'navaja' en México (Aguilar, 201) ${ }^{7}$, fila en Texas (Wagner, $\mathbf{P}$, 253) y, burlescamente, filomena 'cuchillo' en la coa chilena (J. Vicuña Cifuentes, Coa, jerga de los delincuentes chilenos, Santiago, 1910). De filero 'cuchillo, puñal' (cf. Wagner, M, 534) deriva el verbo filerear 'herir o matar con arma blanca' (Trejo, 109) o fileriar 'to knife someone' (G. C. BArker, Pachuco: an American-Spanish argot, Univ. of Arizona, 1950, p. 33; Wagner, P, 253), y de aquí -quizá por cruce con filete 'lonja de carne'- flletear 'matar', usado también en Texas con la acepción de 'cortar con cuchillo o navaja's.

$\S 4$. Tasajear. Menos usado que los anteriores, obedece a idéntico tipo de extensión semántica: propiamente "hacer tasajos de las reses' (R. M. Gutiérrez Eskildsen, "Cómo hablamos en Tabasco", $I L, 1,1934$, p. $3^{01}$ ), y de ahí 'hacer pedazos a una persona, matarla' (cf. Santamaría, M): "Entre los cuatro lo tasajearon en menos que canta un gallo". El mismo significado tiene en Nicaragua (A. Valle, Diccionario del habla nicaragüense, Managua, 1948). En otras regiones de América, 'inferir muchas heridas en el cuerpo de una persona o de un animal' (Rubio, A, II, 272; Santamaría, M, con referencias a otros países). En la Argentina ha experimentado la misma ampliación de sentido el verbo achurar 'elegir la parte de la res o achura que es de mayor preferencia' y también 'matar' (Battini, $B D H, 7$, p. 3oo; Kany, 26).

$\S 5$. Torcer o retorcer el pescuezo es uno de los procedimientos más comunes para matar las aves. Aplicado a personas se encuentra en el español general, como equivalente no sólo de 'ahorcar', sino de 'matar' en cualquier forma violenta (DRAE). Quebrar o apretar el cogote debieron aplicarse en un principio únicamente a los animales, aunque cogote sea un derivado de coca 'cabeza' en general (DCEC).

7 En la germanía del siglo xvn, filosa 'espada' y filosos 'cuchillos' (JuAN Hidalgo, Romances de germania con el vocabulario, Madrid, 1779, p. 173; $\mathbf{R}$. Salillas, El delincuente español. El lenguaje, Madrid, 1896, p. 286; L. Besses, Diccionario de argot español, Barcelona, s.a., p. 78).

8 G. Cerda, B. Cabaza y J. Farías, Vocabulario español de Texas, Austin, 1953. Filetiar como sinónimo de filiar 'comer' en la germanía mexicana, lo recoge Jiménez, 201. Alfilerear 'herir con daga o navaja o cuchillo' (A. B. GaArder, "Notes on some Spanish terms in the Southwest", $H, 37,1944$, p. 331) deriva de alfiler 'arma blanca' (Trejo, 107 y 116 ), también usado en España como 'puñal' (Besses, Dice. de argot, 20), o de alfilero 'navaja' (GAARdER, "Notes", 332; Wagner, $\mathrm{P}, 253)$. Analíticamente, le metieron su alfiler 'lo mataron', en el habla popular mexicana (Padrón, 161). 
Lo mismo me inclino a pensar de acogotar, que el DRAE define 'matar con herida o golpe dado en el cogote', sin alusión alguna al sacrificio de los animales. Mi impresión parece ser confirmada por la explicación que de este verbo da Covarrubias, uno de los primeros lexicógrafos que lo recoge (1611): "Matar con golpe que se da en el cogote, como ordinariamente se matan las reses mayores". Éste sigue siendo el procedimiento más empleado para matar conejos. Acaso pudiera pensarse lo mismo, en lo que respecta a la extensión primitiva, de apercollar y apergollar, bastante usados en México como sinónimos de 'asesinar': se lo apergollaron (Jiménez, 162) es resultado de una representación sumamente gráfica la frase clavarle el pico a uno ='hacerle clavar el pico', 'matarlo' (cf. infra, hincar el pico, § 13). Inspirada en la lenta muerte de los cerdos, se oye alguna vez en México la expresión desangrar a alguien (como a puerco): "Le dio su fierrito y lo desangró para robarlo"10. Creación festiva, de reciente cuño y de uso esporádico, es el verbo dedetizar 'asesinar, escabechar', derivado de las iniciales del insecticida $D D T$; sería, pues, 'hacer una gran matanza, una hecatombe; matar como a chinches'; por lo menos, eso se esperaría; pero yo tínicamente lo he oído referido a una sola víctima: "A su primo lo dedetizaron hace más de un año".

$\S$ 6. A piolar. Derivado de piola 'cordel o hilo corto y delgado' (Malaret; Santamaría, M), que se identifica con el término náutico castellano piola 'cordel' (DCEC) ${ }^{11}$ y con el antiguo pihuela 'correa con que se aseguraban los pies de los halcones y otras aves'. El verbo apiolar significaba ya en la Edad Media, no sólo 'poner pihuela a las aves', sino también 'atar un pie con el otro de un animal muerto en la caza para colgarlo por ellos' ${ }^{\prime 2}$, de donde, inmediatamente, se derivaría la acepción de 'cazar, matar', que aparece ya en Lope de Vega (Fuenteovejuna, I, xv; cf. DCEC). Aunque en México se usa muy poco apiolar con el sentido de 'matar', tuvo cierta popularidad a raíz del asesinato de Trotzky, a causa de una etimología popular: el asesino se sirvió, para cometer su crimen, de un piolet (bastón de alpinista) con el que fracturó el cráneo de su víctima. Por ese motivo

9 Desgañotar es en Tabasco 'matar cortando el gañote' (Santamaría, M). Con igual valor, en Puerto Rico y Santo Domingo (Malaret). En el Perú, no obstante, es usual esta acepción tratándose de aves (Malaret).

10 Ideológicamente iguales son las expresiones -muy usadas en la lengua familiar mexicana- sacar a uno el mole o sacar el chocolate o el tepache (la sangre) $=$ 'desangrar, matar'.

11 Lenz quería derivar el chileno piola 'cuerda' del araucano piulu 'hilo delgado', falsa etimología que aún sigue Malaret.

12 En el Libro de buen amor, 991f: "Así enpiuelan el conejo" (cf. la nota de Cejador en su ed. de Clás. cast.). Otro significado secundario de apiolar es el de 'aprisionar, echar grillos' (J. Hrdalgo, Voc. de germania, 155; Covarrubias, s. v. empiolar), que se conserva aún en la lengua del hampa mexicana: "Ni con birlo blando, ni con boleador apiolado" (= 'ladrón preso'; Rubio, R, II, 271). 
se dijo que Trotzky había sido apiolado, y aún hoy algunas personas establecen relación directa entre apiolar y matar con piolet. Pero, como he dicho, apiolar no es verbo de uso frecuente.

$\S 7$. Quitar el pellejo por 'quitar la vida, matar' es expresión de la lengua española general ( $D R A E)$ y muy popular en México, donde también se dice mucho quitar la pielecita. Aún se usa más despellejar, con igual sentido, aplicado también a personas, así como la locución perifrástica darle a uno su despelleje (Padrón, 160), formada sobre expresiones del tipo dar su agua, dar su (de) aplaque, dar mastique, dar su desinfle, etc., todas de igual significado. Desollar, en cambio, se usa muy poco. Con el mismo sentido se emplea pelar: "Si he de entregar la pelleja, que me pelen de una vez" (Padrón, 282); igual en el Brasil (Viotti) y en Santo Domingo: "Una noche lo pelaron entre dos enemigos"13. Trasposiciones como éstas se conocen en gran número de lenguas, por ejemplo en francés: avoir la peau de qqn. 'tuer quelqu'un'14.

\$ 8. Muertas las reses y ya despellejadas, se las abre en canal para sacarles los intestinos, el bofe, el mondongo y demás vísceras. Aplicadas a personas, estas expresiones son bastante comunes en el habla de México, especialmente cuando se trata de muerte ocasionada con arma blanca. Todas ellas pertenecen a la lengua familiar festiva, y son muestra de la despreocupación y confianza con que el pueblo habla de la muerte: "A F. lo abrieron en canal" (Ríos, 489) es una de las más comunes. "Apenas se hizo noche, lo sorprendieron y le sacaron las tripas" (usado en cualquier país de lengua española). No menos popular es la expresión sacar el mondongo (Jiménez, 162), así como el verbo desmondongar ${ }^{\mathbf{1 5}}$ 'destripar, sacar los intestinos a puñaladas' (Santamaria, M) y, en general, 'matar'. Se usa mucho en Cuba (F. Ortiz, Un catauro de cubanismos, La Habana, 1923, p. 185) referido a animales y especialmente a personas; lo mismo en el Perú, como sinónimo de 'asesinar' (Kany, 26). En Nicaragua se dice mondonguear 'sacarle a uno las tripas a cuchilladas' (A. VAlLE, Dice. del habla nicaragüense). Desconchinflar el menudo es algo menos usual; se emplea sobre todo "cuando el difunto recibió herida penetrante de vientre, con arma blanca" (Padrón, 160).

$\S$ 9. Hacer chicharrón a uno, 'matarlo, especialmente en forma

13 Manuel A. Patín Maceo, Dominicanismos, Ciudad Trujillo, 1947. Cuerear 'sacar el cuero de los animales muertos' (BDH, 7, p. 222) ha extendido sus significados en otras direcciones: en México 'azotar, golpear' (P. BoYDBowman, El habla de Guanajuato, México, 1960, p. 305), que el DRAE considera exclusivo del Ecuador; también 'murmurar' o 'ganar a uno en el juego' (Santamaría, M), pero no 'matar'. En Colombia, descuerar (Cuervo, Apuntaciones criticas, 934) con las mismas acepciones.

14 H. Bauche, Le langage populaire, Paris, 1928, s. v. peau.

15 Derivado de mondongo 'vientre, tripas', correspondiente a bandullo. Cf. salmantino esbandujar 'destripar' y extremeño esfandufar 'despanzurrar' (DCEC). 
violenta y con saña'16; expresión muy popular en todo el país. Existe también el verbo chicharronear (Santamaría, M). En Nicaragua se dice hacerse de un chicharrón 'matar a alguno, romper un objeto, echar a perder algo' (A. VALLE, Dice.). Sobre el modelo hacer chicharrón se forman a cada paso expresiones semejantes que también significan matar: hacer cebiche ${ }^{\mathbf{1 7}}$, hacer barbacoa ${ }^{\mathbf{1 8}}$, hacer carnitas $^{\mathbf{1 9}}$, hacer picadillo (común en España y otros países americanos ${ }^{20}$ o hacer moronga ${ }^{21}$, empleada sobre todo en caso de atropellamiento.

$\S$ 10. Escabechar, poner en escabeche como a los pescados -lo cual implica una muerte previa - es uno de los eufemismos festivos más populares en México (Jiménez, 200) y en cualquier región donde se hable español. De aquí, la lengua popular mexicana ha ampliado el significado de otros verbos próximos, $y$, como sinónimos de matar, usa también enlatar (como a las sardinas; enviar o meter al ataúd) y empacar. En Cuba, embarrilar 'matar' (Kany, 26). También se echa a la fiambrera a quien se asesina: el fiambre es el cadáver, pues está frio.

$\S$ 11. También se pueden cazar personas: "A Beto lo cazaron cuando salía de su casa"; por lo común se emplea cuando se mata con arma de fuego y por sorpresa. Es muy usado (Padrón, 160). Quizá lo sea todavía más venadear 'cazar venados', conocido en toda Centroamérica, y también en toda ella aplicable a personas; significa, en rigor, 'matar alevosamente con arma de fuego en el campo o en un camino, espiando y tirando a traición de entre los matorrales' (Santamaría, M; A. VAlle, Dice. nicaragüense); pero en general puede aplicarse al hecho de matar con arma de fuego en cualquier circunstancia o lugar. Mucho menos popular son chacalear (Jiménez, 200) y azorrillar, ya anticuado: "Al presumido le dieron su ley fuga cerca de Morelia. Entoavía está la cruz sobre el camino rial onde lo azorrillaron"'22. En Colombia, pavear (cazar pavos) por 'matar a mansal-

16 Chicharrón = 'trozo de gordura o de carne de cerdo, frito en su propia pringue'. Por extensión, 'cualquier carne en pedacitos, frita y tostada'.

17 Platillo que se hace con pescado, chile y otras hortalizas picadas. Santamaría, A, y el DRAE (s. v. cebiche) lo dan como privativo del Perú.

18 Carne asada, al horno o bajo tierra, y generalmente aderezada con salsa picante.

19 'Carnes fritas y adobadas en tacos y bocadillos, que se venden comúnmente en las fritangas callejeras' (Santamaría, M).

20 Picotear es en Tabasco y en Cuba 'matar con crueldad, cercenando el cuerpo a machetazos o golpes de arma cortante' (Santamaría, M). Cf., por otro lado, la expresión general en México echarse a alguien al pico 'matar'.

${ }^{21}$ Moronga 'morcilla, salchicha' (Malaret); el mismo cliché en España: hacer salchicha a alguien.

22 Cf. Santamaría, M. El origen de este verbo no es cinegético; primitivamente significaba "poner a uno boca abajo, en cuatro pies; era práctica de los bandoleros y asaltantes de caminos, que obligaban a los pasajeros de diligencias a adoptar tal postura". En el habla actual ha pasado a significar "amedrentar'; se usa especialmente el participio: "Me lo traen muy azorrillado". Zopilotearse 
va, asesinar' (J. Toвón, Colombianismos, Bogotá, 1953, p. 195). Kany (p. 27: to kill) reúne para otros países: caimanear, buitrear, pichonear, pajarear y tortolear.

$\S$ 12. Metáforas de origen taurino, basadas en la muerte del toro, son dar la puntilla 'matar', o más concretamente 'rematar, ultimar' (usado en todas partes); dar el descabello 'id.' (Padrón, 161) y descabellar, producir cualquier tipo de muerte, pero sobre todo si es instantánea; dejar para el arrastre, que Malaret recoge como mexicanismo, aunque su empleo debe ser, sin duda, mucho más amplio (no sólo en el sentido general de 'maltratar', sino también en el específico de 'matar'); y dejar pa las mulillas, idéntico ideológicamente al anterior $^{23}$.

\section{O R I R}

$\S$ 13. Como las aves, el que muere hinca el pico. En México esta locución tiene dos significados familiares: el de 'desfallecer, acabársele a uno las energías' (Santamaría, M) y el de 'morir', que es el más general. Se usa en todos los países de habla española (DRAE). Puede también decirse, simplemente, la hincó. En México es todavía más común decir clavar el pico (Ríos): "El que a los veinte no es valiente, a los treinta no es casado y a los cuarenta no es rico, es gallo que clavó el pico" (=hombre muerto: Rubio, R, I, 179) ${ }^{24}$. Se construye además con otros verbos: cerrar el pico ('callarse' o 'morir'), abrir el pico, doblar el pico (Jiménez, 161), usado también en el Ecuador y el Perú (Malaret), colgar el pico (cf. colgar los guantes, etc.), parar o bajar el pico y torcer el pico (cf. el párrafo siguiente).

$\$$ 14. También como las aves, se tuerce la cabecita al morir: "Cuando yo tuerza la cabecita, de seguro que no estaré solo". Se dice además agachar la cabecita. De igual manera, torcer el pescuezo o torcer el quiote (del náhuatl quiotl, 'tallo floral de los magueyes': C. A. Robelo, Dice. de aztequismos, $3^{\text {a }}$ ed:, p. 459; popular por 'cuello'). Se dice también torcer los ojos y, de manera muy especial, torcer el rabo (F. Ramos i Duarte, Dice. de mejicanismos). Sin em-

a uno 'matarlo' procede de zopilotear 'comer con voracidad', que no significa 'cazar zopilotes' (cff. comerse a alguien, merendarse a uno, echárselo al plato, etc. $=$ 'matar'). La idea de ser comido por animales origina abundantes expresiones de tipo distinto, que no vamos a estudiar aquí: echar a los gusanos, a las ratas, a los perros, a los zopilotes, a los tiburones, etc.

23 Es probable que también tenga relación con la muerte dada a los animales el antiguo (ya en Correas, 557) dejar patitieso (cf. infra, § 19).

24 Puede significar también 'entrar en período de decadencia suma': "Matiana lo había hechizado... y desde entonces clavó el pico" (Santamaría, M). Puede tener además el sentido de 'dormirse'. En el Río de la Plata, paralelamente, clavar la guampa (= cuerno de la res): "Vendré a ser dueño de una mujercita joven y linda hasta el día mesmo en que me toque clavar la guampa" (Kany, 22). 
bargo, esta última expresión, en su forma original -torcer la puerca el rabo ${ }^{25}$-, significa propiamente 'demostrar desagrado o contrariedad', sentido con el que, en esencia, la había recogido ya Cuervo para Colombia: "Aqui torció la puerca el rabo: éste es el momento crítico, aquí está la dificultad" (A puntaciones, 741). Por 'morir', en Texas, retorcer la cola (G. Gerda, Vocab. español de Texas). En Guatemala, parar la cola es también 'morirse' (L. SANDoval, Semántica guatemalense, Guatemala, 1941-42, p. 196), expresión que puede oírse con relativa frecuencia en México; en el Brasil tiene el mismo valor bater com a cola na cêrea (Viotti).

$\S$ 15. Semejante a parar o alzar el pico, y más todavía a levantar la pata (cf. \$ 19), es la expresión popular levantar el ala 'morir'. Podría quizá relacionarse también con ahuecar el ala (Padrón, 160) $=$ morir, con la idea de 'irse'26. Posiblemente haya habido un cruce de los dos tipos de expresiones. También muere quien da los últimos aletazos, frase empleada sobre todo para referirse a la agonía; Santamaría, M, recoge papalotear 'aletear las aves' y 'boquear, agonizar, hacer los movimientos últimos por vivir' (nunca lo he oído). Paralelamente, dar los últimos coletazos -como el pescado-, usual en la costa del Pacífico.

$\S$ 16. De la tauromaquia creo que están tomadas las dos expresiones siguientes. E1 torero obliga al toro a doblar la cerviz para poder entrar a matar. Herido de muerte, el toro dobla los remos y cae por tierra. Siendo acciones que se suceden inmediatamente antes de la muerte ya inevitable, nada de extraño tiene que las expresiones correspondientes hayan pasado a designar el acto mismo de morir, aplicado a personas" ${ }^{27}$ : "Nacho dobló los remos antes de medianoche". Relacionadas por la forma con las anteriores -aunque ideológicamente independientes-, también para 'morir' se usan las expresiones doblar los codos y doblar las manos. Su significado primitivo es el de 'ceder, transigir, doblegarse' (Santamaría, M); por 'morir' son muy' populares en Honduras, en Nicaragua (Kany, 22) y, en general, en toda Centroamérica. Acaso de allí nos haya venido esta acepción; sin embargo, téngase en cuenta que también rendir y rajarse pueden significar en México 'morir'.

25 Se dice además torcer la marrana (o la chocha, o la tunca), el rabo (o la cola) (Santamaria, M). En la conocida canción popular española, el rabo del asno queda bien tieso: "Ya estiró la pata, / ya arrugó el hocico, / con el rabo tieso, / adiós, adiós, Perico".

26 Frecuentísimos son en todos los idiomas los eufemismos que presentan a la muerte como una partida, como una salida o fuga de este mundo; he aquí algunos ejemplos mexicanos tomados al azar: irse, liar el petate, volar (al cielo), pelarse, irse con los angelitos, navegar, emprender el viaje, largarse, pintarse, etc. En caló, alarse significa 'irse' (Besses, Dice. de argot).

27 El $D R A E$ recoge sólo, para bajar o doblar la cerviz, el significado figurado de 'humillarse, deponiendo el orgullo y altivez'. 
$\$$ 17. Las expresiones que significan 'caer' se usan comúnmente con el valor secundario de 'morir'. De ellas, la más empleada es azotar, especialmente en la forma jazotó la res! Según las circunstancias, expresará una caída o la muerte; en algunos lugares parece inclinarse ya por lo segundo: "AAzotó la res! = Cayó redondo, se murió"28. Idéntico significado tiene dar el azotón (no uno cualquiera, sino el definitivo). La muerte es "más absoluta" 29 cuando se azota como chango viejo (Santamaría, M) [cayendo desde lo alto de un árbol]. De aquí la expresión, muy popular por 'morir', dar el changazo (Ríos, $484)^{30}$.

$\S$ 18. Quedarse como (un) pajarito. Es una de las expresiones más conocidas, que alude, por lo general, a una muerte tranquila ${ }^{31}$. Se usa en todos los países de habla española ( $D R A E)$; era una de las más generalizadas ya en la lengua clásica, con doble significado: "Quedarse como un pajarito. El que muere con sosiego, y el niño que se queda dormido" (Correas, 635). Sobre este modelo se forman otras expresiones: quedar como ratoncito, quedar como (una) palomita, como (un) pichoncito, como el gato (de la tía Cleta). De una persona que muere repentinamente, se explica que no dijo ni pio o ni pio dijo ${ }^{32}$.

$\S 19$. Quedarse patitieso supongo que se inspira también en la muerte de los animales ${ }^{33}$; aunque desde antiguo se use aplicado a personas (Correas, 557). Idéntica imagen origina la expresión familiar estirar la(s) pata(s), usadísima en todo el dominio de la lengua española (la forma plural parece más propia de Hispanoamérica: $I L$,

28 E. Cortichs, El habla de Tepotzotlán, México, $195^{1}$ (tesis), p. 66. Azotar tiene otros muchos significados: golpear; pagar, aflojar la mosca; saldar una deuda; vagabundear. En la Argentina, arrojarse al agua.

$29 \mathrm{Al}$ parecer, cabe la posibilidad de que la muerte sea incompleta, ya que en muchos casos se dice de alguien que "se murió toditito" o que "se murió de a tiro"...

30 "Changazo. En estilo festivo, caída estrepitosa, en cualquier sentido: azotón, porrazo, panzazo, costalada. Usado en la frase dar el changazo, morir" (Santamaría, M). También significan 'caerse', y por extensión 'morir', las frases similares dar el chanclazo, dar el angelazo, el cuartazo, el costalazo, el talegazo, el putazo, el tablazo, el chingadazo, el fregadazo, el reatazo, el bonetazo (esta última, exclusivamente 'morir').

31 Aunque no sea precisamente tranquila ni sosegada la muerte de las aves: las convulsiones y aleteos de su agonía suelen ser impresionantes.

32 La frase no tiene probablemente origen "animal". En el siglo xvn, Correas (p. 644) atestigua: "Sin decir Dios valme; sin poder decir Dios valme: Cuando por accidente repentino murió o le mataron". Pio requiere, naturalmente, un tiempo aún menor para su expresión. Además, no decir ni pio = permanecer en el más absoluto silencio.

${ }^{33} \mathrm{La}$ violenta distensión muscular de las extremidades posteriores no se produce (o quizá no es tan evidente) en el hombre como en las bestias. Además, lo que se estira es precisamente la pata, no la pierna. No obstante, Covarrubias (s. v. pata): "Patitiesso, el que se ha elado". 
1, 311; 2, 125; Santamaría, M). En México, la frase presenta gran número de variantes, debido a la riqueza de disfemismos que suelen sustituir en ella a patas: estirar la pezuña (Wagner, P, 260), estirar las panteras, las llantas, los rieles, los cacles [= los pies] (cf. Jiménez, 72 y 183), los tenis (Padrón, 159), etc. Las expresiones correspondientes del portugués revelan con mayor claridad que las patas pertenecen a animales: esticar o pernil, esticar os cambitos [ = patas de cerdo, jamones] (cf. Viotti, s.v. esticar). El verbo estirar puede sustituirse, a su vez, por restirar o por alargar: “¡Desde cuándo alargó las patas ese cuate!"'34

Al morir, no sólo se estiran, sino que también se pueden levantar o parar las patas (Kany, 22) ${ }^{35}$, aunque lo más frecuente sea, en México, parar los tenis (Jiménez, 44; Padrón, 159). Otras variantes vulgares: parar los cacles y levantar las de galopar (cf. también parar la cola, § 14). Estas últimas expresiones implican la idea de caerse, de azotar como res quedando patas arriba.

$\S$ 20. Soltar el pellejo, 'morir' en todas partes, lo mismo que quitar el pellejo, 'matar' (cf. \$7). La expresión puede construirse con los verbos entregar, dar y dejar (Rubio, R, II, 82), y en vez de pellejo no es raro oír pelleja (Padrón, 159), piel o pielecita. Estas frases son comunes en la lengua clásica (Covarrubias); en ellas, pellejo aparece usado como sinónimo inmediato de vida. Se emplea así constantemente en frases proverbiales: "Si he de entregar la pelleja, que me pelen de una vez" (Padrón, 282); "Quien se casa viejo, presto da el pellejo"36; "Pagar con el pellejo" (Casares); "Jugarse el pellejo" (Santamaría, M). También suele decirse, en México, entregar y botar el cuero o el envase ${ }^{37}$, y todavía más frecuentemente entregar la zalea (Jiménez, 161), colgar la zalea (sobre el arquetipo colgar los guantes; cf. también colgar el pico, \$ 13), perder la zalea (Padrón, 16o) y sobre todo estacar el cuero (Malaret) o la zalea (Santamaría, M). Esta última frase, estacar la zalea, es la más popular, acaso por su expresividad. Estacar cueros es en gran parte de América 'extender y estirar pieles sobre el suelo, clavándolas con estacas para mantenerlas restiradas, secándose al sol'. De ahí el que, al menos en Norte y Centroamérica (Malaret), estacar el cuero propio o la zalea sea 'mo-

${ }^{34}$ Lo mismo en Cuba (E. Rodríguez Herrera, "El plebeyismo en Cuba", BdFS, 8, $1954-55$, p. $4^{26}$ ) y en el habla popular española (Besses, Dicc. argot, p. 125).

35 Usual en toda Centroamérica y posiblemente en gran parte de la América meridional. Para Chile, cf. A. Rabanales, "Recursos lingǘsticos de expresión de la afectividad", $B d F S$, 10 (1958), p. 294.

${ }^{36}$ L. MARTínez KLEISER, Refranero general ideológico español, Madrid, 1953, núm. 3906o, con más ejemplos.

${ }^{37}$ Largar la tira en Cuba (cf. Rodríguez Herrera, "El plebeyismo...", p. 426$)$. 
rir'38: "Están en ansia de que yo estaque la zalea" (Santamaría, M). En alguna ocasión puede oírse encerar la zalea, como acción más consumada, muerte más plena. Igual significado tiene el verbo estaquear, propiamente 'estirar los cueros frescos con estacas' (BDH, 7, p. 222), muy usado en la Argentina, donde además significa 'estirar a un hombre entre cuatro estacas por medio de maneadores amarrados a las muñecas de las manos y garganta de los pies' ${ }^{\mathbf{3 9}}$. En México el verbo se usa muchísimo menos que la locución estacar la zalea, pero no es enteramente desconocido: “¡Pobre viejito! Yo creo que pronto va a estaquiar".

$\S 21$. Pelechar. Aunque no sea muy usado, puede oírse a veces como sinónimo de morir; se dice también apelechar: "No puede ser él, porque (a)pelechó hace más de un mes". Conserva a la vez, y con mayor generalidad, su significado propio: "cambiar el pelo o las plumas los animales' ${ }^{\prime 40}$. El cambio semántico es fácil de explicar: al renovarse el pelo o la pluma, es más en un principio lo que se cae que lo que se repone; de ahí que pelechar haya pasado a significar 'tener poco pelo' por estarlo cambiando, e incluso 'perder el pelo': "¡Pobre; está todo pelechadito!” (cf. apelechar, despelechar, espelechar): y en Nebrija (Vocab. español-latino) "Pelechar el ave $=$ deplumesco". De 'perder el pelo' a 'dejar, entregar el pelo o la piel', y de aquí a considerar pelo o piel como sinónimos de 'vida' (cf. supra, $\$ 20)$, hay sólo un paso ${ }^{41}$. En esta última etapa, además, pudo influir beneficiosamente el uso de pelarse 'irse' en el sentido de 'morir' -general en México ${ }^{42}-$ y de pelar 'matar' (cf. $\$ 7$ ), así como un cruce, por razones de proximidad fonética, con espichar 'morir' 43 .

El Colegio de México.

Juan M. Lope Blanch

38 En Venezuela, según Malaret, estacar significa 'herir con arma blanca', y estacar el cuero 'matar'. Estacar es, en el primer caso, derivado de estaca 'puñal, cuchillo'.

39 D. Granada, Voc. rioplatense. Cf. además M. Toro Gisbert, "El idioma de un argentino", $B R A E$, 9 (1922), p. 7og.

${ }^{40} \mathrm{Y}$ no sólo, como dice el DRAE, 'echar los animales pelo o pluma'. En efecto, Covarrubias precisa: "Bolver a echar pelo nuevo". Así también en Nicaragua (VALLE, Dicc.).

41 Por otra parte, esta metáfora es común en otros idiomas; en italiano, por ejemplo, lasciarci le penne (E. Coseriu, Creación metafórica en el lenguaje, Montevideo, 1956, p. 26)

42 "Pelarse. Escabullirse, y también morir. Lo mismo en Colombia y Venezuela" (Santamaría, M). Usual, sobre todo, en la forma pelar gallo (Wagner. M, 542), pelarse de casquete (Jiménez, 161) y pelar rata(s), muy popular esta última en toda la América central (Malaret).

43 En Tabasco, según Santamaría, M, pelechar significa también, entre jugadores, 'pelar a uno, dejarlo concienzudamente sin blanca'; lo que, en el español general, se llama desplumar. 